\title{
A PSICANÁLISE DE FREUD E DE WINNICOTT: UMA ANÁLISE À LUZ DA FILOSOFIA HEIDEGGERIANA.
}

\author{
Jones de Oliveira Barbosa 1; Caroline Vasconcelos Ribeiro 2 \\ 1: Bolsista PIBIC/CNPQ, Graduando em Filosofia, Universidade Estadual de Feira de Santana, e-mail: \\ jonesoliveira@live.com \\ 2: Orientadora: Dr ${ }^{a}$ Caroline Vasconcelos Ribeiro, Departamento de Ciências Humanas e Filosofia, Universidade Estadual de \\ Feira de Santana, e-mail: carolinevasconcelos@ hotmail.com
}

PALAVRAS-CHAVE: Psicanálise, Filosofia, Heidegger, Winnicott, Freud.

\section{INTRODUÇÃO}

O presente resumo tem a finalidade de apresentar os resultados finais provenientes da pesquisa intitulada "A Psicanálise de Freud e de Winnicott: uma análise à luz da filosofia heideggeriana". A referida pesquisa contou com o fomento da bolsa de Iniciação Científica, na modalidade PIBIC/CNPQ, na Universidade Estadual de Feira de Santana. O objetivo geral da pesquisa consistiu em analisar se a crítica que Martin Heidegger dirigiu à psicanálise de Freud poderia ser estendida à psicanálise de Donald Winnicott. Isso porque Heidegger argumenta que Freud se serviu de pressupostos herdados das ciências naturais para conceber a sua metapsicologia e, consequentemente, o conceito de inconsciente. Após o exame da crítica heideggeriana dirigida a Freud, analisamos a psicanálise de Winnicott numa tentativa de verificar se nela poderíamos encontrar as pretensões de objetividade científico-naturais indicadas pelo filósofo alemão no arcabouço teórico freudiano. Para Heidegger, Freud se serve de uma semântica fisicalista para versar sobre o psiquismo. Ao pensá-lo como uma máquina movida por uma força interna e constante, a pulsão, Freud teria destinado ao existir humano conceitos com pretensões de objetividade típicas das ciências naturais. A crítica do filosofo incide sobre a metapsicologia freudiana, especificamente sobre os conceitos metapsicológicos de: aparelho psíquico, pulsão, inconsciente e repressão. De acordo com a perspectiva heideggeriana, tais conceitos foram postulados à luz da filosofia neokantiana e dos pressupostos das ciências naturais. O conceito de inconsciente, por exemplo, teria sido postulado pelo pai da psicanálise para tornar explicáveis fenômenos cujas motivações conscientes não eram suficientes para a elucidação. $\mathrm{O}$ estabelecimento de leis que regem $\mathrm{o}$ psiquismo e o estabelecimento do inconsciente como fator causal de sintomas, sonhos e outros fenômenos humanos apontam, segundo Heidegger, para uma afinidade freudiana com a identidade científico-natural.

\section{MATERIAL, MÉTODOS OU METODOLOGIA (ou equivalente)}

O plano de trabalho ao qual está atrelado este resumo baseia-se em uma pesquisa bibliográfica, cuja tarefa consistiu numa rigorosa leitura de obras dos autores principais, a saber, Heidegger, Winnicott e Freud, além de comentadores relacionados ao tema do plano. Nosso primeiro passo metodológico consistiu em uma apropriação da crítica heideggeriana em relação à psicanálise de Freud, para tanto, levantamos os principais argumentos apresentados por Heidegger na obra Seminários de Zollikon (2001). Como a crítica de Heidegger se dirige à metapsicologia, priorizamos o estudo de textos ligados a esta parte especulativa da psicanálise. Para tanto, fizemos o exame dos seguintes escritos freudianos: Esboço de psicanálise (1996a); Algumas lições elementares de psicanálise (1996b); Repressão (1996c); A pulsão e seus destinos Freud, (1996d) Um estudo autobiográfico (1996e), O Inconsciente (2006) e A fixação no trauma, o inconsciente (2014). Com o objetivo de entendermos a evolução dos conceitos freudianos ao longo de sua obra, utilizamos o Vocabulário de Psicanálise de Laplanche e Pontalis (2001). Esse foi o nosso segundo passo 
metodológico. O terceiro passo consistiu em examinar capítulos das seguintes obras de Winnicott: $O$ ambiente e os processos de maturação (1983); Os bebês e suas mães (2012); Explorações psicanalíticas (1994); Da pediatria à psicanálise (2000); A criança e seu mundo (1982). Para melhor compreensão da psicanálise winnicottiana fizemos o exame da obra $A$ teoria do amadurecimento de D. W. Winnicott da comentadora Elsa Dias (2003). O estudo dos textos winnicottianos foi feito em cotejamento com a obra A linguagem de Winnicott Dicionário das palavras e expressões de Jan Abram (2000). Para o exame das bases ontológicas da psicanalise de Winnicott e de Freud nos servimos de textos de Loparic, Fulgencio, Assoun e Ribeiro

\section{RESULTADOS E/OU DISCUSSÃO (ou Análise e discussão dos resultados)}

A obra "Seminários de Zollikon" (2001) contém as palestras ministradas por Heidegger e atas dos diálogos e cartas trocadas entre o psiquiatra Medard Boss e o filósofo. É nessa obra que encontramos a crítica que Heidegger direcionou à psicanálise de Freud; em linhas gerais, o filósofo aponta que o pai da psicanálise ergueu sua ciência em um solo gestado pela ciência da natureza. Ao analisar a herança epistemológica subjacente ao arcabouço teórico freudiano Heidegger afirma que "a metapsicologia de Freud é a transferência da filosofia neokantiana para o homem. Por um lado, ele tem as ciências naturais e, por outro, a teoria kantiana da objetidade". (HEIDEGGER, 2001, p. 247). A crítica de Heidegger à psicanálise de Freud concentra-se na parte especulativa da psicanálise: a metapsicologia. O recurso a construções auxiliares sem referência empírica e que funcionam como ficções heurísticas para tornar dados observáveis explicáveis consiste, segundo Kant (1990), em um recurso legítimo para as ciências da natureza. Os conceitos metapsicológicos - como pulsão, inconsciente, aparelho psíquico, repressão - não têm suporte empírico, porém são de suma importância para as pesquisas psicanalíticas, pois a partir dos mesmos torna-se possível explicar o material observável clinicamente. Na obra "Esboço de Psicanálise", Freud (1996a) afirma que sua ciência se serve de construções auxiliares do mesmo modo que ciências mais duras, a física e a química. Para Assoun (1983), a comparação entre sua teoria e a física e a química aparece sempre que Freud pretende caracterizar a natureza científica de sua psicanálise. Loparic (2001) destaca que Freud utilizou o método especulativo ou método de construções auxiliares, inspirados nos modelos de ciências naturais da sua época. À luz da filosofia de Heidegger e do posicionamento de epistemólogos estudiosos da obra freudiana, notamos que a identidade epistemológica da psicanálise de Freud afina-se com as das ciências da natureza. Tendo como referência os pressupostos da filosofia heideggeriana nos perguntamos se seria possível destinar a crítica de Heidegger à psicanálise winnicottiana. Questionamos: será que Winnicott, ao pensar o amadurecer humano, se serve das categorias fisicalistas denunciadas por Heidegger como componentes centrais da psicanálise de Freud? A partir do exame da obra winnicottiana e de textos de pesquisadores como Loparic e Fulgencio, notamos diferenças radicais entre a psicanálise freudiana e a de Winnicott. Ao invés de se servir da ideia de um aparelho psíquico em busca de satisfação pulsional, Winnicott descreveu o existir humano a partir de sua condição de não-integração e de sua total dependência das provisões ambientais. De acordo com essa perspectiva, não podemos falar em vicissitudes da pulsão, inconsciente reprimido e aparelho psíquico quando nos referimos ao bebê em seus primeiros meses. No texto "Psicanálise do sentimento de culpa" Winnicott critica o fato de a análise freudiana sobre a culpa centrar-se no questionamento sobre a economia pulsional. Nesse sentido, aponta que neste modo de análise podemos localizar um determinismo implícito, bem como "(...) a premissa de que a natureza humana pode ser examinada objetivamente e que podem ser aplicadas a ela as leis que são conhecidas em Física" (WINNICOTT, 1983, p.20). Vimos que Winnicott (2000, p.164), ao destinar seu olhar para as relações iniciais entre mãe e bebê, afirma ser necessário abrir mão da ótica que avalia tudo em termos de satisfação pulsional e 
nos convida a pensar tais relações a partir de uma linguagem que considera os cuidados ambientais dispensados ao neonato. Em sua crítica à linguagem freudiana, o psicanalista inglês afirma: "As palavras equilíbrio homeostático evitam certos aspectos mais sutis que surgem ao nosso olhar, quando observamos esse relacionamento com a atenção que lhe é devida". (WINNICOTT, 1983, p. 400). Com a condução de nossa pesquisa, notamos que Winnicott nos convida a olhar para a relação mãe-bebê sem recorrer à semântica fisicalista.

\section{CONSIDERAÇÕES FINAIS (ou Conclusão)}

Vimos que Heidegger atesta que a psicanálise freudiana está ancorada em um modelo de ciência tributário das ciências da natureza. Fulgencio (2003, p. 155) esclarece que, ao fazer uso de especulação o pai da psicanálise está se enquadrando em um modelo de se fazer ciência que tem Kant como sua referência filosófica. Trata-se do programa kantiano para a ciência da natureza, o qual faculta o uso de princípios puros, ideias, sem referentes empíricos para organizar fenômenos observáveis. E é esse programa que, na perspectiva heideggeriana, encontramos no arcabouço metapsicológico freudiano. Apoiados em Araújo (2011) e Dias (2002) percebemos que a linguagem teórica de Winnicott não está ancorada em conceitos especulativos e sim em um olhar para as relações iniciais mãe e bebê a partir de uma descrição dos cuidados ambientais. Vimos Winnicott defendeu ser necessário abrir mão da ótica que avalia tudo em termos de satisfação pulsional e nos convidou a pensar tais relações a partir de uma linguagem que considera os cuidados ambientais dispensados ao neonato. À luz de textos de Loparic, Fulgencio e Ribeiro, podemos dizer que a psicanálise winnicottiana descreve o existir humano sem recorrer ao conceitos metapsicológicos de pulsão e de aparelho psíquico, o que implica dizer que Winnicott "realizou uma mudança no estatuto ontológico do objeto de estudo da psicanálise." (FULGENCIO, 2006, p.12). Ao invés do estudo do funcionamento da máquina psíquica, Winnicott nos ofertou um estudo da conquista da integração e do amadurecimento considerando os cuidados ambientais. Como Winnicott não se serve dos conceitos metapsicológicos criticados por Heidegger, nos sentimos autorizados a afirmar que a crítica dirigida ao cientificismo-natural de Freud não serve para Winnicott. Esse psicanalista não tenta acessar os fenômenos por meio de especulações - ancoradas em pretensões de objetividades típicas das ciências naturais - mas através de uma tentativa de aproximação descritiva, em função disso, concluímos que não seria factível pensar que crítica de Heidegger a Freud poderia ser destinada a Winnicott.

\section{REFERÊNCIAS:}

ARAÚJO, C. A. S. “O ambiente winnicottiano”. In: Winnicott na Escola de São Paulo. Elsa Oliveira Dias e Zeljko Loparic (orgs.). - São Paulo: DWW Editorial, 2011.

ASSOUN, P-L. Introdução à epistemologia freudiana. Tradução: Hilton Japiassu. Rio de Janeiro: imago, 1983.

DIAS, E. O. “A trajetória intelectual de Winnicott”. In: Natureza Humana 4(1): 111-156, Jan.jun. 2002.

FREUD, S. "Esboço de psicanálise”. In: Obras psicológicas completas de Sigmund Freud. Rio de Janeiro: Imago Editora, 1996a. Vol. XXIII.

. "O Inconsciente". In: Obras psicológicas completas de Sigmund Freud. Tradução de Luiz Alberto Hanns. - Rio de Janeiro: Imago Editora. Vol. II, pp.14 - 74, 2006. 
. "O Inconsciente". In: Obras psicológicas completas de Sigmund Freud. Tradução de Luiz Alberto Hanns - Rio de Janeiro: Imago Editora. Vol. II, pp.14 - 74, 2006.

FULGENCIO, L. "As especulações metapsicológicas de Freud” in: Natureza Humana Revista Internacional de Filosofia e Psicanálise. São Paulo: EDUC, vol. 5.n 1, 2003.

Winnicott e uma psicanálise sem metapsicologia. 2006. Disponível em <https://www.researchgate.net/publication/255991888_Winnicott_e_uma_psicanalise_sem_m etapsicologia> Acessado em 04 de agosto de 2018

HANNS, L. Dicionário comentado do alemão de Freud. Rio de janeiro: Imago Editora, 1996.

HEIDEGGER, M. Seminários de Zollikon. Tradução de Gabriella Arnhold, Maria de Fátima de Almeida Prado. - São Paulo: EDUC; Petrópolis, RJ: Vozes, 2001.

LAPLANCHE, J. \& PONTALIS, J.B. Vocabulário de Psicanálise. Tradução: Pedro Tamen. São Paulo: Martins Fontes, 2001.

LOPARIC, Z. "Além do Inconsciente - sobre a desconstrução heideggeriana da psicanálise". In: Natureza Humana - Revista Internacional de Filosofia e Psicanálise. São Paulo: EDUC, vol. 3.n 1, pp. 91-140, 2001.

SANTOS, E. S. "Winnicott e Heidegger: indicações para um estudo sobre a teoria do amadurecimento pessoal e a acontecência humana". In: Natureza Humana 9(1): 29-49, jan.jun. 2007.

WINNICOTT, D. W. Explorações Psicanalíticas. Porto Alegre: Artmed, 1994.

O ambiente e os processos de maturação: estudos sobre a teoria do desenvolvimento emocional. Tradução de Irineo Constantino Schuch Ortiz. - Porto Alegre, Artmed, 1983.

Da Pediatria à Psicanálise. Rio de Janeiro: Imago, 2000. 